\title{
Khemvirg Puente Martínez, Cómo se decide el gasto público en México. Congreso y proceso presupuestario durante la democratización (1994-2016), México, 2017, UNAM/Ediciones La Biblioteca, 356 pp.
}

Reseña por Adriana del Rosario Báez Carlos*

Licencia Creative Commons Atribución-NoComercial (CC BY-NC) 4.0 Internacional

Perfiles Latinoamericanos, 28(56) | 2020 | e-ISSN: 2309-4982 DOI: http://doi.org/10.18504/pl2856-017-2020

\section{6)}

n aspecto crucial de un Estado democrático es la definición de sus prioridades a partir de los criterios de asignación del gasto público. En México, es una novedad la irrupción del Poder Legislativo federal como actor central del proceso de definición de prioridades nacionales, a partir del ejercicio de su facultad para participar en el diseño de la política económica y sancionar el gasto público" (p. 15), subraya Khemvirg Puente Martínez en su libro Cómo se decide el gasto público en México. Congreso y proceso presupuestario durante la democratización (1994-2016).

En una bien lograda aplicación de la ciencia política a un estudio de caso, esta obra se adentra en un proceso que comenzó a definirse en la Cámara de Diputados mexicana a partir de 1997. Para ello, el autor se auxilia de una adecuada exposición teórica, una exhaustiva recopilación de evidencia empírica, el análisis de datos apoyado en indicadores delineados por clásicos de la teoría legislativa, y de una metodología mixta que incluye técnicas cuantitativas y cualitativas.

Se trata de un estudio original, que contribuye a enriquecer el conocimiento sobre las dinámicas que experimenta el Poder Legislativo mexicano a raíz de su pluralización y en el marco de los gobiernos divididos que experimenta México desde 1997.

Puente Martínez se propone conocer el impacto que la transición a la democracia en México tuvo sobre uno de los procesos legislativos más importantes: el de la definición del gasto público. Al hacerlo, logra trascender el saber (hoy

* Doctora en Ciencia Política por la Facultad de Ciencias Políticas y Sociales de la Universidad Nacional Autónoma de México (unam). Pertenece al sni Nivel I. Profesora y secretaria académica del Centro de Estudios Políticos, FCPyS de la UnAm | cabaadriana64@politicas.unam.mx 
casi general) de que el cambio político experimentado entre las postrimerías del siglo xx y los albores del xxi debilitó al Poder Ejecutivo y fortaleció al Legislativo: "Uno de los efectos de la democratización en México ha sido el cambio gradual en el proceso presupuestario y en los mecanismos mediante los cuales se definen las prioridades de gasto del Estado. Pasó de ser una decisión centralizada en el Ejecutivo, excluyente y opaca, a una decisión colegiada, plural y descentralizada, con un elevado número de actores con capacidad de veto, pero poco transparente" (p. 19), señala el investigador nacional.

En una revisión histórica del Poder Legislativo en México, Puente Martínez se centra en el proceso de crecimiento paulatino de poderes presupuestarios de esa rama del Estado a partir de 1997, cuando la presencia mayoritaria de la oposición en la Cámara de Diputados permitió a sus grupos parlamentarios contar con recursos para acceder en condiciones de igualdad a la negociación del presupuesto, y desafiar el poder del partido gobernante.

El estudio que presenta este texto, da un paso adelante respecto de los análisis que se han venido realizando sobre el Congreso mexicano, en particular, y las legislaturas de América Latina, en general, a partir del retorno a las democracias en la región.

Una vez que los Congresos dejaron de ser oficialías de parte de los Ejecutivos en la región, se multiplicaron los análisis sobre su integración, las fórmulas electorales y su impacto en las características de los grupos parlamentarios en América Latina, en su disciplina y cohesión, en la productividad de las legislaturas, en los poderes legislativos y constitucionales de los presidentes, en las prácticas de negociación y en las votaciones, todo lo cual ha venido ampliando el conocimiento sobre su comportamiento. Con todo, el estudio de Khemvirg Puente va más allá, se adentra en un proceso legislativo en específico, quizá el más importante de los Congresos: el de la definición de "la bolsa” y su distribución.

Una vez identificado que México pasó de tener una asamblea pasiva, refrendadora de las iniciativas del Ejecutivo, a contar con un Congreso plural, integrado democráticamente, con una actitud proactiva, el autor se adentra en el estudio de un proceso nodal del Poder Legislativo: la definición, en un entorno plural, de los recursos que se destinarán a la operación de las políticas públicas y su distribución.

Puente Martínez revive, con atractivos detalles, el proceso mediante el cual la democratización fue incluyendo a nuevos actores en las negociaciones y otorgando autonomía a sectores antes cooptados por el partido gobernante, como los sindicatos y grupos políticos locales. Observa cómo las prácticas de intercambio de beneficios, también llamadas clientelares, se han fortalecido en el proceso parlamentario del pacto presupuestal. 
El estudio parte de la hipótesis de que en el pacto presupuestal, los legisladores mexicanos, con la limitante de la prohibición a la reelección consecutiva (que se levantó hasta la reforma político-electoral de 2014), actúan más como representantes de intereses alejados de cualquier ideología y como voceros de partidos, patrones, mentores y aliados, con objetivos concretos relacionados con la vigencia de carreras políticas individuales, que en la representación de sus electores o el interés general de la nación.

Las consecuencias de su actuación en ese consenso son la estabilidad en el equilibrio institucional del régimen, el afianzamiento del clientelismo y la permanencia del statu quo, seńala Khemvirg, y revela que, de acuerdo con la evidencia, en este proceso impera la lealtad política en torno a principales que determinan las carreras políticas de los legisladores, y no la disciplina partidista.

En el texto, salido de la imprenta a mediados de 2018, Puente indaga diferentes mecanismos causales que ayudan a explicar la reasignación de partidas presupuestarias en cada negociación anual, como el desmantelamiento de los instrumentos de control político del Ejecutivo sobre el Legislativo y los legisladores; la emergencia de actores políticos con capacidad, formal o informal, de veto, y condiciones de autoritarismo subnacional y sectorial que sustituyen a los poderes que antes concentraba el Ejecutivo.

Encuentra que la centralidad del Poder Legislativo en este proceso se hizo posible en el marco de gobiernos divididos, en los que se elevó la proporción de votos contrarios al proyecto original de presupuesto enviado por el Ejecutivo a la Cámara de Diputados.

Ante la multiplicación de los actores involucrados en el proceso, se fue construyendo un pacto presupuestal, como mecanismo de cooperación política en un proceso más complejo que el simple intercambio de recursos económicos por favores políticos, pues se ve afectado por factores como la gobernabilidad, el clientelismo, el corporativismo, los cacicazgos regionales, sectoriales y partidarios, en medio de la opacidad por la ausencia de rendición de cuentas, sostiene el autor.

Para Khemvirg Puente, el pacto presupuestal es un mecanismo que sirve para superar las diferencias ideológicas o partidarias entre los actores involucrados en la definición de prioridades a través de la redistribución del gasto público. Este pacto se alcanza a partir de 1997 en el espacio que la Constitución Política de 1917 facultó para ello: la Cámara de Diputados.

El análisis del proceso presupuestario en México se realiza desde un enfoque neoinstitucional, que posibilita al investigador constatar el proceso de institucionalización que ha permitido al Congreso mexicano decidir con autonomía y capacidad técnica en el proceso de negociación del presupuesto. La intensidad con que un Poder Legislativo ejerce la función presupuestaria está determinada por algunos factores exógenos, como las facultades constitucionales de las 
ramas del Estado, la colaboración entre poderes, o el número de actores con veto, pero también por el nivel de institucionalización de la legislatura, que le da capacidad técnica para hacerlo, subraya Puente.

El libro recorre diversas etapas en el proceso de institucionalización del Poder Legislativo en México: a) de 1917 a 1934, la construcción del régimen constitucional posrevolucionario, b) de 1934 a 1964, la del presidencialismo, c) de 1964 a 1988, la de liberalización, d) de 1988 a 1997, la de democratización, y e) de 1997 a 2010 la de institucionalización.

En esta última, el proceso de transformación en la normatividad interna del Congreso y las comisiones encargadas del presupuesto y la cuenta, así como el crecimiento del peso de la oposición y de su intervención en el dictamen legislativo, permitieron que esta rama del Estado pasara de rubricadora (rubber stamp) de las iniciativas del Ejecutivo, a ser una legislatura influyente, que modifica e incluso rechaza los proyectos del presidente.

La Ley Orgánica de 1999, el Estatuto de Organización Técnica y Administrativa, el Servicio de Carrera de la Cámara de Diputados, la reforma constitucional en materia presupuestaria de 2004 y la Ley de Presupuesto, Contabilidad y Gasto Público Federal de 2006 son disposiciones que fortalecieron al Congreso en este proceso. Permitieron que fuera la Cámara de Diputados la que aprobara el presupuesto previo examen, discusión y, en su caso, modificación del proyecto original; revisarlo y analizarlo en un plazo de hasta 68 días, con el apoyo de las comisiones ordinarias en los temas de su competencia; limitar al Ejecutivo en la reasignación de partidas, y otorgar un papel especial al Centro de Estudios de Finanzas Públicas de la Cámara, para apoyar el proceso de análisis y evaluación presupuestal.

Para ponderar la capacidad institucional de la legislatura en cuanto a influir en la aprobación del presupuesto público, Puente retoma un índice utilizado por Joachin Wehner en un estudio para el Wold Bank Institute, el cual mide las capacidades legal-institucionales (poderes de enmienda, costo de la reconducción, flexibilidad del Ejecutivo) y organizacionales (tiempo de escrutinio, capacidad de comisiones e información y capacidad técnica) de las legislaturas. Y encuentra que en 2010 México se ubicó, junto con Estados Unidos, en los niveles más altos registrados para países con sistemas de gobierno presidencial.

En el proceso presupuestario influyen, de igual manera, la mecánica de la estructura de incentivos formales (normas de comportamiento y carrera política) e informales (negociación política, clientelismo y cabildeo) sobre los legisladores y la forma en la que los partidos administran el poder parlamentario para construir las mayorías legislativas que permitan su aprobación.

La institucionalidad democrática ha adoptado características de la informalidad y permite a los actores involucrados en la redistribución del poder y los 
recursos, utilizar el entramado institucional para favorecer estructuras clientelares que reproducen equilibrios a través de la redistribución de recursos, sostiene el autor.

Khemvirg Puente encuentra que las fuerzas políticas que se benefician del gasto público están representadas en el pacto presupuestal a través de los legisladores federales, partidos políticos y grupos de interés.

El proceso de discusión y aprobación del presupuesto público es el espacio donde se hace visible la disputa del mayor número de actores del sistema político y económico del país, que se hacen presentes para influir en los criterios de la política distributiva y la reasignación de sus partidas.

¿Bajo qué condiciones se distribuye el gasto público en México? ¿Qué actores intervienen en el proceso decisorio y quiénes tienen capacidad de vetar el pacto? ¿Son los partidos políticos y el gobierno los únicos que afectan el destino del gasto? ¿Cómo se ha modificado el proceso de negociación presupuestaria en los años del cambio político en México? Son preguntas que Puente se plantea y trata de responder con la investigación que presenta el texto.

Sumado a su rigor científico, el libro es atractivo por la cantidad de información precisa que aporta, por adentrarse en uno de los procesos de negociación política más relevantes en las democracias contemporáneas y por la riqueza de las experiencias que comparten los actores políticos entrevistados.

Cómo se decide el gasto público en México es un libro de obligada lectura para los estudiosos de la ciencia política, los especialistas en el poder legislativo y para todo aquel interesado en conocer a detalle los procesos políticos que se viven en las democracias contemporáneas. 
